\title{
Determinants of Youth Engagement with Health Information on Social Media Platforms in United Arab Emirates
}

\author{
Niyi Awofeso1, Yunes Gaber ${ }^{1}$, Moyosola Bamidele ${ }^{2}$ \\ ${ }^{1}$ School of Health and Environmental Studies, Hamdan Bin Mohammed Smart University, Dubai, UAE \\ ${ }^{2}$ Deapartment of Statistics, University of Ilorin, Nigeria \\ Email: a.awofeso@hbmsu.ac.ae,200007166@hbmsu.ac.ae, bamidelemoyo@gmail.com
}

How to cite this paper: Awofeso, N., Gaber, Y. and Bamidele, M. (2019) Determinants of Youth Engagement with Health Information on Social Media Platforms in United Arab Emirates. Health, 11, 249-262. https://doi.org/10.4236/health.2019.112022

Received: January 30, 2019

Accepted: February 23, 2019

Published: February 26, 2019

Copyright $\odot 2019$ by author(s) and Scientific Research Publishing Inc. This work is licensed under the Creative Commons Attribution International License (CC BY 4.0). http://creativecommons.org/licenses/by/4.0/

\section{Open Access}

\begin{abstract}
Since most social media platforms are accessible anytime and anywhere where Internet connections and smartphones are available, the invisibility of the reader raises questions about accuracy, appropriateness and comprehensibility of social media communication. This purposive sampling study of 120 participants aged 18 - 35 year in UAE was conducted between September and December 2017, and explored commonly used social media platforms, frequency of use of social media for accessing health related information, and approaches for assessing the trustworthiness of health information. Results indicate that Whats App (95\%), Instagram (87\%) and Youtube (82\%) were the most commonly used social media platforms among respondents. Majority of respondents $(81 \%)$ indicated that they regularly access social media to get health-associated information. About $55 \%$ of respondents with non-chronic health status relied on unsolicited messages to obtain health-related information. Doctors' health blogs $(21 \%)$ and social media sites of international healthcare organizations $(20 \%)$ constitute the most trusted source of health information among respondents, with UAE government health agencies' social media accounts trusted by $15 \%$ of respondents. Cardiovascular diseases, diabetes and hypertension were the most commonly searched topics on social media (29\%), followed by nutrition (20\%) and skin care (16\%). Majority of respondents (41\%) rely on reliability of Google search results, $22 \%$ check for health information only from "reliable" social media sites, while $8 \%$ utilize "logic" to ascertain reliability of health information. Utilizing popular social media platforms for posting reader-friendly health information will achieve high coverage. Improving youth digital literacy will facilitate easier access to trustworthy information on the internet.
\end{abstract}

\section{Keywords}

Social Media, UAE, Youth Engagement, Digital Literacy 


\section{Introduction}

Social media refer to internet-based and mobile services that allow users to participate in online exchanges, access information, join online communities and contribute content. They include blogs, Wikis, social networking sites, media sharing sites and virtual world content. In the health industry, social media offer a new way to engage with consumers, with many health agencies and individual healthcare practitioners using a variety of social media tools to share information about clinical and public health issues. Social media tools are woven into many young people's day-to-day lives, for communication, accessing information and learning. Youths are in communication with multiple contacts using a wide variety of different media and media devices every day in accessing information and informal learning [1].

A significant proportion of research on youth engagement with social media focuses on its adverse mental health effects on youth. In 2017 the UK's Royal Society of Public Health and Youth Health Movement published a report titled \#StatusOfMind in which they emphasized the intrinsic links between social media and mental health, in a country where $91 \%$ of youth regularly use social networking sites and rates of anxiety and depression among this age group have increased by $70 \%$ in the past 25 years. The report includes a league table of social media platforms according to their impact on young people's mental health. YouTube tops the table as the most positive, with Instagram and Snapchat coming out as the most detrimental to young people's mental health and wellbeing. While social media use was linked with increased rates of anxiety, depression, poor sleep and cyber bullying, the authors also found that social media significantly improves access to expert health information and effective online emotional support. The report's recommendations include introduction of a pop-up heavy usage warning on social media; social media platforms to identify users who could be suffering from mental health problems by their posts, and discretely signpost to support; social media platforms to highlight when photos of people have been digitally manipulated [2].

The potential of social media platforms to improve community health through social inclusion, improved access to health information, peer-to-peer networking, online health consultations and use of apps for health monitoring is huge, given its high penetration among key populations. The 2015 Pew Research Center study on Social Media and Friendships found that $76 \%$ of US teenagers use social media, with $71 \%$ of them being regular users. About $68 \%$ of teenagers claim that social media provide them with support during difficult times, while $46 \%$ of teenage girls agree that social media empower them to speak out about the things they care about. Concerning social inclusion, $83 \%$ of teenagers say that social media make them feel more connected to their friends [3].

Important variables in assuring positive contributions of social media to youth health care include access to social media sites, credibility of accessed health information, usability of health information sites, health literacy and digital litera- 
cy. Currently, it is estimated that 2.62 billion people worldwide use social media, corresponding to $71 \%$ of internet users. With 1.87 billion active users, Facebook is the leading social media platform in terms of reach and scope. In the United Arab Emirates (UAE) in 2016, 99\% of the population were active social media users, with WhatsApp having a $93 \%$ penetration rate among the population [4]. Health-related posts are not subject to the same level of scrutiny as posts which may influence terrorist operations or impact religious sensitivities. Thus, ascertaining the credibility of health-related information found on the Internet and how patients, their caregivers, and lay health consumers use such information is an issue of concern. Credibility, also referred as believability, is a quality perceived by individuals, who are not always able to discern with their cognitive capacities genuine information from the fake one. Some of the so-called health gurus on social media do not have a formal health-related tertiary education, and they appear to take advantage of a gray zone in health care-an area where modern, evidence-based science has not yet provided definitive answers-to proffer opinions and even 'cures' that are highly suspect [5].

Messages, notifications, and alerts sent through social networks must be relevant, timely, and well-written to be effective. Design guidelines for posts from healthcare practitioners and healthcare organizations should pay particular attention to: message content; message frequency and timing; voice and tone; engaging followers and facilitating discussion; profile information and design; building a following and promoting a social network presence. The process of engaging users to co-create content, to rate, rank and comment on communications, is increasingly perceived to give a heightened authenticity to health messages, improving trust in, and building users' relationships with, organizations [6]. Health literacy is an important precondition for seeking, accessing and utilizing health information on the internet. Assuring high quality health literacy for adolescents is important in the United Arab Emirates to facilitate government's Vision 2021 objectives of superior health and intellectual attainment of young people, as well as to reduce very high prevalence of obesity and other behavioral and dietary risk factors for health. Most studies of health literacy among UAE's young people indicate a low percentage of highly health literacy, highlighting the need to improve health literacy training, especially among Emirati males [7].

Digital literacy describes capabilities that fit someone for living, learning, working, participating and thriving in a technologically advanced society. It is the ability to seek, find, understand, and appraise health information from electronic sources and apply the knowledge gained to addressing or solving a health problem. It comprises six domains: Communication, collaboration and participation; Teaching, learning and self-development; Information, data and media literacies; Creation, innovation, scholarship; Technical proficiency, and; digital identity, wellbeing, safety and security. Most of the popular social media platforms are note very active in health information provision, for example, the possibility of finding content on the leading causes of death related to NCDs on Fa- 
cebook is only about $10 \%$ [8].

This study explores the popularity of social media platforms among youth aged 18 - 35 years, as well as sources of health information and how participants determine the credibility and accuracy of health-related information in UAE. We also sought responses on usability of health information sites on social media, and the extent to which information accessed is actioned.

\section{Methods}

An online internet survey was designed using Google Forms app and posted on the Internet between September and December 2018. The inclusion criteria were that participants had to be UAE residents, and aged between 18 and 35 years. The online survey consisted of 10 questions, including demographic information survey related to gender, nationality, and employment status. The survey was posted on popular social media networks in UAE. Participation was voluntary and no monetary or gift incentives were provided. Inclusion criteria were that participants be between 18 and 35 years and be resident in UAE. As only English and Arabic versions of the survey instrument were available, only English and Arabic speakers were eligible to participate in the survey. Exclusion criteria were residents younger than 18 or older than 35, non-UAE residents and non-English and Arabic speakers.

We adapted the technology acceptance model and theory of reasoned action framework [9] on the core influences of UAE youths' intention to use, and actual use of social networking sites for health and wellness information (Figure 1). Descriptive and Inferential data analyses were undertaken on SPSS version 17 using cross tabulation at 0.05 alpha level to test the significance of the study research statement.

\section{Results}

As at the end of the survey, there were 137 responses, of which 17 were excluded as they did not meet the age-related eligibility criterion. Females constituted 73 of the $120(68.3 \%)$ eligible respondents. UAE nationals constituted approximately $58 \%$ of total respondents. Almost half $(47 \%)$ of respondents were resident in Dubai emirate and majority of respondents were in the 20 - 25 years age group.

The statistical analysis on 120 eligible respondents showed that Whatsapp was the most common used social medium accounting around 95 percent and 86 percent of them using it daily. Instagram and Youtube usage among respondents is also high, at 86.7 and 81.7 , respectively, with about half of them using it daily. These findings are consistent with that in the United States where $90 \%$ of young adults regularly use social media [10]. Unlike Whatsapp, which has no gender bias in usage, usage of Instagram and Youtube platforms was slightly more common among females than males (Instagram: $91.8 \%$ of female participants, $78.7 \%$ of males; YouTube: $89.0 \%$ of females, $70.2 \%$ of males). Interestingly, the 


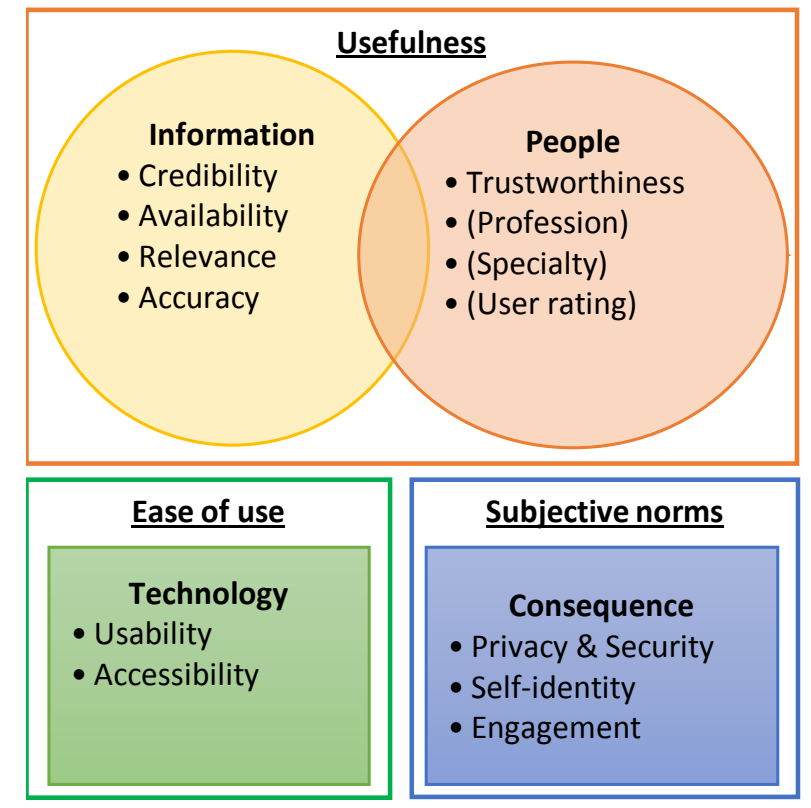

Figure 1. Intention to use social networking sites for health and wellness information access.

24 hours temporary image messaging platform "Snapchat" had higher usage rate among participating females ( $89.0 \%$ of females, $63.8 \%$ of males).

Concerning nationality, Emirati nationals significantly prefer using Twitter than Facebook as normal social networking platforms (85.1\% using Twitter, $34.3 \%$ using Facebook) while non-Emirati respondents reported comparable usage rates for both platforms (71.4\% using Twitter, 65.3\% using Facebook). Emirati nationals' usage for Twitter is similar among students compared with employees. Other social media such as Imo and Flickr have usage rate less than $15 \%$ and are the least commonly used platforms (Table 1 ).

Majority of respondents (80.8\%) indicated that they regularly accessed social media to access health-associated information, and 32.5\% reported that they frequently used social media as tool for obtaining information about health products or services. A 2012 report based on US survey of health consumers indicated that $42 \%$ of respondents use social media to access health information [11]. As shown in Table 2, Females were more likely to use social media for sake of health-related information than males $(71.8 \%$ of females to $28.2 \%$ of males; Pearson Chi-Square $=4.435$ ).

As expected for youth participants, around $82.4 \%$ of them have not experienced any chronic diseases, and female participants are less likely to have chronic diseases than males $\left(\mathrm{OR}^{\star}=0.33\right.$; Pearson Chi-Square $\left.=5.359\right)$. Students showed lower chronic health conditions compared with other participants who were employed. There was no significant difference in chronic disease prevalence between Emirati nationals and non-Emiratis (Table 3).

More than half of respondents (55\%) with non-chronic health status reported that they relied on unsolicited messages (e.g. unsolicited social media text or 
Table 1. Social_media ${ }^{\star}$ Gender cross tabulation.

\begin{tabular}{|c|c|c|c|c|c|}
\hline & & & & & \\
\hline & & & Male & Female & \\
\hline & & Count & 38 & 57 & 95 \\
\hline & Twitter & $\%$ within Gender & $80.9 \%$ & $78.1 \%$ & \\
\hline & & $\%$ of Total & $31.7 \%$ & $47.5 \%$ & $79.2 \%$ \\
\hline & & Count & 25 & 33 & 58 \\
\hline & Facebook & $\%$ within Gender & $53.2 \%$ & $45.2 \%$ & \\
\hline & & $\%$ of Total & $20.8 \%$ & $27.5 \%$ & $48.3 \%$ \\
\hline & & Count & 12 & 21 & 33 \\
\hline & Linkedin & $\%$ within Gender & $25.5 \%$ & $28.8 \%$ & \\
\hline & & $\%$ of Total & $10.0 \%$ & $17.5 \%$ & $27.5 \%$ \\
\hline & & Count & 37 & 67 & 104 \\
\hline & Instragram & $\%$ within Gender & $78.7 \%$ & $91.8 \%$ & \\
\hline & & $\%$ of Total & $30.8 \%$ & $55.8 \%$ & $86.7 \%$ \\
\hline & & Count & 30 & 65 & 95 \\
\hline & Snapchat & $\%$ within Gender & $63.8 \%$ & $89.0 \%$ & \\
\hline & & $\%$ of Total & $25.0 \%$ & $54.2 \%$ & $79.2 \%$ \\
\hline & & Count & 44 & 70 & 114 \\
\hline & Whatsapp & $\%$ within Gender & $93.6 \%$ & $95.9 \%$ & \\
\hline Socinl medina & & $\%$ of Total & $36.7 \%$ & $58.3 \%$ & $95.0 \%$ \\
\hline - & & Count & 15 & 18 & 33 \\
\hline & Telegram & $\%$ within Gender & $31.9 \%$ & $24.7 \%$ & \\
\hline & & $\%$ of Total & $12.5 \%$ & $15.0 \%$ & $27.5 \%$ \\
\hline & & Count & 33 & 65 & 98 \\
\hline & Youtube & $\%$ within Gender & $70.2 \%$ & $89.0 \%$ & \\
\hline & & $\%$ of Total & $27.5 \%$ & $54.2 \%$ & $81.7 \%$ \\
\hline & & Count & 12 & 25 & 37 \\
\hline & Google & $\%$ within Gender & $25.5 \%$ & $34.2 \%$ & \\
\hline & & $\%$ of Total & $10.0 \%$ & $20.8 \%$ & $30.8 \%$ \\
\hline & & Count & 13 & 33 & 46 \\
\hline & Skype & $\%$ within Gender & $27.7 \%$ & $45.2 \%$ & \\
\hline & & $\%$ of Total & $10.8 \%$ & $27.5 \%$ & $38.3 \%$ \\
\hline & & Count & 8 & 10 & 18 \\
\hline & Imo & $\%$ within Gender & $17.0 \%$ & $13.7 \%$ & \\
\hline & & $\%$ of Total & $6.7 \%$ & $8.3 \%$ & $15.0 \%$ \\
\hline & & Count & 7 & 5 & 12 \\
\hline & Flickr & $\%$ within Gender & $14.9 \%$ & $6.8 \%$ & \\
\hline & & $\%$ of Total & $5.8 \%$ & $4.2 \%$ & $10.0 \%$ \\
\hline & & Count & 47 & 73 & 120 \\
\hline & & $\%$ of Total & $39.2 \%$ & $60.8 \%$ & $100.0 \%$ \\
\hline
\end{tabular}

Percentages and totals are based on respondents. a. Dichotomy group tabulated at value 1. 
Table 2. Gender ${ }^{\star}$ Health_Information crosstabulation.

\begin{tabular}{|c|c|c|c|c|c|c|}
\hline & & \multicolumn{4}{|c|}{ Health_Information } & \multirow{2}{*}{ Total } \\
\hline & & Frequently & Sometimes & Rarely & Never & \\
\hline \multirow{4}{*}{ Gender } & Count & 11 & 24 & 8 & 4 & 47 \\
\hline & $\begin{array}{c}\text { \% within } \\
\text { Health_Information }\end{array}$ & $28.2 \%$ & $41.4 \%$ & $47.1 \%$ & $66.7 \%$ & $39.2 \%$ \\
\hline & $\%$ of Total & $9.2 \%$ & $20.0 \%$ & $6.7 \%$ & $3.3 \%$ & $39.2 \%$ \\
\hline & Count & 28 & 34 & 9 & 2 & 73 \\
\hline \multirow[t]{3}{*}{ Female } & $\begin{array}{c}\text { \% within } \\
\text { Health_Information }\end{array}$ & $71.8 \%$ & $58.6 \%$ & $52.9 \%$ & $33.3 \%$ & $60.8 \%$ \\
\hline & $\%$ of Total & $23.3 \%$ & $28.3 \%$ & $7.5 \%$ & $1.7 \%$ & $60.8 \%$ \\
\hline & Count & 39 & 58 & 17 & 6 & 120 \\
\hline \multirow[t]{2}{*}{ Total } & $\begin{array}{c}\text { \% within } \\
\text { Health_Information }\end{array}$ & $100.0 \%$ & $100.0 \%$ & $100.0 \%$ & $100.0 \%$ & $100.0 \%$ \\
\hline & $\%$ of Total & $32.5 \%$ & $48.3 \%$ & $14.2 \%$ & $5.0 \%$ & $100.0 \%$ \\
\hline
\end{tabular}

Table 3. Gender * Chronic_health_condition Crosstabulation.

\begin{tabular}{|c|c|c|c|c|}
\hline & & \multicolumn{2}{|c|}{ Chronic_health_condition } & \multirow{2}{*}{ Total } \\
\hline & & No & Yes & \\
\hline & Count & 34 & 13 & 47 \\
\hline Male & \% within Chronic_health_condition & $34.7 \%$ & $61.9 \%$ & $39.5 \%$ \\
\hline & $\%$ of Total & $28.6 \%$ & $10.9 \%$ & $39.5 \%$ \\
\hline \multicolumn{3}{|l|}{ Gender } & 8 & 72 \\
\hline \multirow[t]{3}{*}{ Female } & $\%$ within Chronic_health_condition & $65.3 \%$ & $38.1 \%$ & $60.5 \%$ \\
\hline & $\%$ of Total & $53.8 \%$ & $6.7 \%$ & $60.5 \%$ \\
\hline & Count & 98 & 21 & 119 \\
\hline \multirow[t]{2}{*}{ Total } & \% within Chronic_health_condition & $100.0 \%$ & $100.0 \%$ & $100.0 \%$ \\
\hline & $\%$ of Total & $82.4 \%$ & $17.6 \%$ & $100.0 \%$ \\
\hline
\end{tabular}

video messages, pop-ups and other advertisements) to obtain health-related information. However, females with non-chronic conditions were more likely to rely on health specific websites, instead of unsolicited messages, for health information compared with males (70\% Vs. 30\%). Employed people are more likely to utilize health specific websites and unsolicited health messages as sources of health information than students (Table 4). Non-communicable diseases (especially diabetes, hypertension and cardiovascular diseases) were the most common health topics of concerned to participants (28.6\%). Nutrition and 
Table 4. Gender * Health_Information Crosstabulation.

\begin{tabular}{|c|c|c|c|c|c|c|}
\hline & & \multicolumn{4}{|c|}{ Health_Information } & \multirow{2}{*}{ Total } \\
\hline & & Frequently & Sometimes & Rarely & Never & \\
\hline \multirow[b]{4}{*}{ Gender } & Count & 11 & 24 & 8 & 4 & 47 \\
\hline & $\begin{array}{c}\text { \% within } \\
\text { Health_Information }\end{array}$ & $28.2 \%$ & $41.4 \%$ & $47.1 \%$ & $66.7 \%$ & $39.2 \%$ \\
\hline & $\%$ of Total & $9.2 \%$ & $20.0 \%$ & $6.7 \%$ & $3.3 \%$ & $39.2 \%$ \\
\hline & Count & 28 & 34 & 9 & 2 & 73 \\
\hline \multirow[t]{2}{*}{ Female } & $\begin{array}{c}\text { \% within } \\
\text { Health_Information }\end{array}$ & $71.8 \%$ & $58.6 \%$ & $52.9 \%$ & $33.3 \%$ & $60.8 \%$ \\
\hline & $\%$ of Total & $23.3 \%$ & $28.3 \%$ & $7.5 \%$ & $1.7 \%$ & $60.8 \%$ \\
\hline \multirow{3}{*}{ Total } & Count & 39 & 58 & 17 & 6 & 120 \\
\hline & $\begin{array}{c}\text { \% within } \\
\text { Health_Information }\end{array}$ & $100.0 \%$ & $100.0 \%$ & $100.0 \%$ & $100.0 \%$ & $100.0 \%$ \\
\hline & $\%$ of Total & $32.5 \%$ & $48.3 \%$ & $14.2 \%$ & $5.0 \%$ & $100.0 \%$ \\
\hline
\end{tabular}

skin care topics were also commonly explored by participants (19.7\% and $15.5 \%$, respectively).

About $90 \%$ of respondents mentioned that they were able to find information they are looking for, $867 \%$ of them are able to understand and act on the provided information, and only $43 \%$ considered those websites are easy to use (Tables 5(a)-(c)).

Scholarly websites such as Pubmed and UAE health organizations websites (e.g. Dubai Health Authority) were not as well regarded with regards to ease of navigation compared with foreign health services websites such as Mayo Clinic and WebMD.com. Table 6 shows gender variations for websites visited by participants to seek health-related information.

Table 6 shows that social media platforms are not commonly used to seek health information by survey participants. The two most commonly used sites were doctors' blogs (21\%) and healthcare organizations (mainly international ones, 20\%).

The impacts of online health resources on personal health decision making were significantly higher among females than males. As per Likert scale, $73 \%$ of respondents who acknowledged the very beneficial impact (L5) of online health resources were females. Employee respondents reported greater impact of online health resources compared with students. There were no significant impact disparities concerning nationality. The responses of participants to the last survey question; "how do you check truthfulness and correctness of such a message?" are tabulated in Table 7.

The majority of respondents utilize Google search engines to seek health information on the Internet. Other surveys indicate that about half of consumers 
Table 5. (a) Were you able to find the information you are looking for? (b) Understand and act on the information; (c) Were user interface elements intuitive and easy to use?

(a)

\begin{tabular}{cc}
\hline Labels & Frequency \\
\hline No & $9.73 \%$ \\
Yes & $90.27 \%$ \\
Total & $100.00 \%$ \\
\hline
\end{tabular}

(b)

\begin{tabular}{cc}
\hline Labels & Frequency \\
\hline No & $13.39 \%$ \\
Yes & $86.61 \%$ \\
Total & $100.00 \%$ \\
\hline
\end{tabular}

(c)

\begin{tabular}{cc}
\hline Labels & Frequency \\
\hline 1 (Hard) & $0.87 \%$ \\
2 & $7.83 \%$ \\
3 & $48.70 \%$ \\
4 & $23.48 \%$ \\
5 (Easy) & $19.13 \%$ \\
Total & $100.00 \%$
\end{tabular}

required some form of navigational support in locating appropriate Web-based health information while on Google or other Internet search engines [12]. Individuals who seek health information on social media sites, and who are devoid of effective navigational support, face higher risks of misinformation [13].

\section{Discussion and Conclusion}

A 2011 nationwide study of US internet users found that $80 \%$ regularly sought health information online frequently. About $29 \%$ of patients viewing health information through social media were viewing other patients' experiences with their respective diseases, and 32\% of US users posted about their friends and family's health experiences on social media. Patients and caregivers usually seek out second opinions; searching the web helps them to discover, via social media (or the internet in general), potential alternatives to diagnoses and/or treatments they otherwise would not know about [14]. These social media trends are mirrored in the UAE context, sometimes with adverse consequences [15]. Out of the 5624 hospitals in the United States, only 1501 are using a form of social media, which equates to approximately $26 \%$. In a survey of healthcare providers in a Texas hospital, $88 \%$ use social media regularly, and they encourage their patients to research their clinical conditions on social media [16]. There is currently no 
Table 6. Which is your most trusted site for health information?

\begin{tabular}{|c|c|c|c|c|}
\hline \multicolumn{2}{|c|}{ Table 6: Which is your most trusted site for health information? } & \multirow{2}{*}{$\begin{array}{c}\text { Female } \\
14\end{array}$} & \multirow{2}{*}{$\begin{array}{c}\text { Male } \\
3\end{array}$} & \multirow{2}{*}{$\begin{array}{c}\text { Total } \\
17\end{array}$} \\
\hline Doctors Blogs & Count & & & \\
\hline & $\%$ within Gender & $25.5 \%$ & $12.0 \%$ & \\
\hline & $\%$ of Total & $17.5 \%$ & $3.8 \%$ & $21.3 \%$ \\
\hline \multirow[t]{3}{*}{ General } & Count & 3 & 7 & 10 \\
\hline & $\%$ within Gender & $5.5 \%$ & $28.0 \%$ & \\
\hline & $\%$ of Total & $3.8 \%$ & $8.8 \%$ & $12.5 \%$ \\
\hline \multirow[t]{3}{*}{ Government entities } & Count & 7 & 5 & 12 \\
\hline & $\%$ within Gender & $12.7 \%$ & $20.0 \%$ & \\
\hline & $\%$ of Total & $8.8 \%$ & $6.3 \%$ & $15.0 \%$ \\
\hline \multirow[t]{3}{*}{$\begin{array}{l}\text { Healthcare Organiza- } \\
\text { tions Count }\end{array}$} & & 12 & 4 & 16 \\
\hline & $\%$ within Gender & $21.8 \%$ & $16.0 \%$ & \\
\hline & $\%$ of Total & $15.0 \%$ & $5.0 \%$ & $20.0 \%$ \\
\hline \multirow[t]{3}{*}{ Scientific databases } & Count & 3 & 2 & 5 \\
\hline & $\%$ within Gender & $5.5 \%$ & $8.0 \%$ & \\
\hline & $\%$ of Total & $3.8 \%$ & $2.5 \%$ & $6.3 \%$ \\
\hline \multirow[t]{3}{*}{ Search engine } & Count & 9 & 2 & 11 \\
\hline & $\%$ within Gender & $16.4 \%$ & $8.0 \%$ & \\
\hline & $\%$ of Total & $11.3 \%$ & $2.5 \%$ & $13.8 \%$ \\
\hline \multirow[t]{3}{*}{ Social media } & Count & 7 & 2 & 9 \\
\hline & $\%$ within Gender & $12.7 \%$ & $8.0 \%$ & \\
\hline & $\%$ of Total & $8.8 \%$ & $2.5 \%$ & $11.3 \%$ \\
\hline \multirow[t]{3}{*}{ Total } & Count & 55 & 25 & 80 \\
\hline & $\%$ within Gender & $100 \%$ & $100 \%$ & $100 \%$ \\
\hline & $\%$ of Total & $68.8 \%$ & $31.3 \%$ & $100 \%$ \\
\hline N/A & Count & 18 & 22 & 40 \\
\hline Total (with N/A) & Count & 73 & 47 & 120 \\
\hline
\end{tabular}

published evidence on UAE's health care providers' roles in motivating health consumers to research social media for their ailments. The general approach in $\mathrm{UAE}$ is for healthcare providers to discourage social media use for researching health conditions [17].

While determinations of the accuracy and reliability of categories of internet sites for accessing health information are beyond the scope of this study, other studies demonstrate that benchmark accuracy scores for health topics contents were significantly higher for scientific resources and foundation/advocacy organizations than for personal commentary (blog) websites. Interestingly, 
Table 7. Fact-checking approaches of participants for internet health messages. $\mathrm{P}=$ percentage.

\begin{tabular}{ccc}
\hline How do you check truthfulness and correctness of such a message? & Number & $\mathbf{P}$ \\
\hline Asking friends & 7 & $6.09 \%$ \\
Asking people in social media & 2 & $1.74 \%$ \\
Checking from reliable/medical sources & 26 & $22.61 \%$ \\
Consultant from expert & 14 & $12.17 \%$ \\
Google search & 47 & $40.87 \%$ \\
No time to check & 6 & $5.22 \%$ \\
Past experience & 3 & $2.61 \%$ \\
Think by mind/logic & 9 & $7.83 \%$ \\
Trying it & 1 & $0.87 \%$ \\
Total & 115 & $100 \%$ \\
\hline
\end{tabular}

Wikipedia and Medscape had the highest website quality measured by DISCERN and JAMA benchmarks for the specialized health topic of idiopathic pulmonary fibrosis [18]. For websites providing information on pancreatic cancer treatments, a study found that alternative therapy websites exhibited the lowest accuracy score, and that nonprofit NGO sites, government and academic websites were more accurate than privately owned and media websites. Websites with higher accuracy were more difficult to read than websites with lower accuracy. In the absence of quality control on the Internet, physicians should provide guidance to patients in the selection of online resources with readable and accurate information [19].

The potential dangers and likely positive benefits of social media use on the health status and outcomes of youth are fairly well established [20]. Engagement with health information on social media has positive and negative benefits. Depending on level of education, health literacy and digital literacy, information obtained on the internet may enhance or compromise health status. An example of the latter is sourcing of harmful content or advice, such as websites or social networks enabling the promotion of self-harm and increasing of suicide risk. Conversely, social media platforms are increasingly utilized to counsel vulnerable individuals to prevent suicide risk and address underlying factors such as depression [21] [22].

This study reveals a comparable level of internet and social media use among youths in UAE compared with similar cohorts in Western nations such as United Kingdom and United States. Given the high level of WhatsApp usage among UAE youth, it is important to tap into its potential for engaging with health consumers. Even in developing nations such as Nigeria, studies indicate that WhatsApp is the preferred mode by health consumers to communicate with government health agencies about diseases [23] [24]. In Brazil, 87\% of doctors use WhatsApp to communicate with patients [25]. Initiatives by UAE healthcare 
organizations to have visible WhatsApp accounts on their internet homepages, in addition to Twitter, Facebook and Youtube account are an important starting point for expanding the use of this encrypted and widely used social media platform. Deploying competent staff to monitor message traffic and provide accurate and timely advice is a subsequent important next step.

Studies indicate that UAE residents generally have a high level of trust on information accessed through social and mainstream media [26]. It is therefore imperative for UAE healthcare organizations to have a stronger social media presence. Since UAE health consumers trust social media, UAE health professionals and organizations must be their trusted source of information online. That way, increasing misinformation of the public on health issues by self-styled experts on the internet can be addressed [27]. It is crucial to assure the usability and information availability of social media sites of UAE health authorities, as consumers currently find them less usable, even less credible, than foreign health sites such asMedScape and WebMD.com [28].

\section{Conflicts of Interest}

The authors declare no conflicts of interest regarding the publication of this paper.

\section{References}

[1] Dewing, M. (2012) Social Media-An Introduction. Canada Parliamentary Information and Research Service. Ottawa, Canada.

https://lop.parl.ca/Content/LOP/ResearchPublications/2010-03-e.pdf

[2] Royal Society of Public Health and Youth Health Movement (2017) \#StatusOfMind: Social Media and Young People's Mental Health and Wellbeing. RSPH, London. https://www.rsph.org.uk/uploads/assets/uploaded/62be270a-a55f-4719-ad668c2ec7a 74c2a.pdf

[3] Lenhart, A., Smith, A., Anderson, M., Duggan, M. and Teens, P.A. (2015) Technology and Friendships. Pew Research Center, Washington DC. http://www.pewinternet.org/2015/08/06/teens-technology-and-friendships/

[4] Statista (2017) Penetration of Leading Social Networks in the United Arab Emirates as of 4th Quarter 2016.

https://www.statista.com/statistics/284504/united-arab-emirates-social-network-pe netration/

[5] Viviani, M. and Pasi, G. (2017) Credibility in Social Media: Opinions, News, and Health Information-A Survey. WIREs Data Mining and Knowledge Discovery, 7, e1209. https://doi.org/10.1002/widm.1209

[6] Schein, R., Wilson, K. and Keelan, J. (2010) Literature Review on the Effectiveness of the Use of Social Media, 2010. University of Toronto, Ontario. https://www.peelregion.ca/health/resources/pdf/socialmedia.pdf

[7] Awofeso, N., Al Zarooni, A., Rabih, Z.A. and Bamidele, M. (2017) Health Literacy Measurements with the Newest Vital Sign Instrument among Adolescents from Dubai, United Arab Emirates. Turkish Journal of Family Medicine and Primary Care, 11, 164-170. https://doi.org/10.21763/tjfmpc.336147

[8] NHS England (2018) A Health and Care Digital Capabilities Framework. NHS, London. 
https://www.hee.nhs.uk/sites/default/files/documents/Digital\%20Literacy\%20Capab ility\%20Framework\%202018.pdf

[9] Zhang, Y. (2013) College Students' Uses and Perceptions of Social Networking Sites for Health and Wellness Information. Information Research, 17, Paper 523. http://InformationR.net/ir/17-3/paper523.html

[10] Pew Research Centre (2018) Social Media Use in 2018. Pew Research Centre, Washington DC. http://www.pewinternet.org/2018/03/01/social-media-use-in-2018/

[11] PWC Health Research Institute (2012) Social Media "Likes" Healthcare-From Marketing to Social Business.

https://www.pwc.com/us/en/health-industries/health-research-institute/publication s/pdf/health-care-social-media-report.pdf

[12] Lee, K., Hoti, K., Hughes, J.D. and Emmerton, L. (2017) Dr Google Is Here to Stay But Health Care Professionals Are Still Valued: An Analysis of Health Care Consumers' Internet Navigation Support Preferences. Journal of Medical Internet Research, 19, e210. https://doi.org/10.2196/jmir.7489

[13] Del Vicario, M., Bessi, A., Zollo, F., et al. (2016) The Spreading of Misinformation Online. Proceedings of the National Academy of Sciences of the United States, 113, 554-559. https://doi.org/10.1073/pnas.1517441113

[14] Fox, S. (2011) Health Topics. Pew Internet, Washington DC. http://www.pewinternet.org/2011/02/01/health-topics-2/

[15] Pew Research Center (2015) Social Media Usage, 2005-2015. Pew Research Center, Washington DC. http://www.pewinternet.org/2015/10/08/social-networking-usage-2005-2015/

[16] Surani, Z., Hirani, R. and Elias, A. (2017) Social Media Usage among Health Care Providers. BMC Research Notes, 10, 654.

https://doi.org/10.1186/s13104-017-2993-y

[17] Samir, A. (2017) Be Wary of Health Advice on Social Media, Doctors Warn. Gulf News, 31 March.

http://gulfnews.com/news/uae/society/be-wary-of-health-advice-on-social-media-d octors-warn-1.1999583

[18] Fisher, J.H., O’Connor, D., Flexman, A.M., Shapera, S. and Ryerson, C.J. (2016) Accuracy and Reliability of Internet Resources for Information on Idiopathic Pulmonary Fibrosis. American Journal of Respiratory and Critical Care Medicine, 194, 218-225. https://doi.org/10.1164/rccm.201512-2393OC

[19] Storino, A., Castillo-Angeles, M., Watkins, A.A., et al. (2016) Assessing the Accuracy and Readability of Online Health Information for Patients with Pancreatic Cancer. JAMA Surgery, 151, 831-837. https://doi.org/10.1001/jamasurg.2016.0730

[20] Frith, E. (2017) Social Media and Children's Mental Health-A Review of the Evidence. Education Policy Institute, London.

https://epi.org.uk/wp-content/uploads/2017/06/Social-Media_Mental-Health_EPIReport.pdf

[21] Luxton, D.D., June, J.D. and Fairall, J.M. (2012) Social Media and Suicide: A Public Health Perspective. American Public Health Association, 102, S195-S200. https://doi.org/10.2105/AJPH.2011.300608

[22] Nous Group (2012) Independent Evaluation of Beyondblue. https://www.beyondblue.org.au/docs/default-source/research-project-files/bw0265. pdf?sfvrsn=33739de9_0 
[23] Adesina, T.I., Niyang, M., Gobir, D.B. and Nwandu, D.A. (2017) Social Media and Disease Surveillance in Nigeria e the Role of WhatsApp. Annals of Global Health, 83, 19-20. https://doi.org/10.1016/j.aogh.2017.03.042

[24] Health Media (2017) WhatsApp-The Digital Future of Healthcare in India. http://ehealthmedia.in/whatsapp-digital-future-healthcare-india/

[25] Boulos, M.N.K., Giustini, D.M. and Wheeler, S. (2016) Instagram and WhatsApp in Health and Healthcare: An Overview. Future Internet, 8, 37.

[26] Dajani, H. (2017) Four-Fifths of UAE Residents Trust Country's Media Outlets, Survey Finds. The National.

https://www.thenational.ae/uae/four-fifths-of-uae-residents-trust-country-s-mediaoutlets-survey-finds-1.683459

[27] De Freitas, J., Falls, B.A., Haque, O.S. and Bursztajn, H.J. (2013) Vulnerabilities to Misinformation in Online Pharmaceutical Marketing. Journal of the Royal Society of Medicine, 106, 184-189. https://doi.org/10.1177/0141076813476679

[28] Lauterbach, C.V. (2016) Exploring the Usability of E-Health Websites. http://usabilitynews.org/exploring-the-usability-of-e-health-websites/ 